\title{
Storytelling for Promoting Social Cohesion in the Marginalized \\ Communities: A Study of Chautari Nataks
}

\author{
Madhu Giri, PhD*
}

\begin{abstract}
The notion of storytelling in playback theatre (Chautari Natak) suggests a dialogue between performer and audience. This dialogue in the public sphere can evoke collective understanding on political and natural disaster victims, and cultivate grounds of negotiation for micro levels of misunderstanding in socio-cultural issues. One of the main objectives of the paper is to analyze methodological intervention employed by the Chautari Natak to initiate sharing/communication between ex-combatant and the local community. Based on field observation and interviews, I argue that the Chautari Natak, as methodological innovation for social dialogue, transforms personal stories into avenues for the socio-cultural empowerment of the participants and promotion of social cohesion. The Chautari Natak performance could be linked to a description of community performance as a way to overcome loneliness and reduce the distance between cultural groups, status groups, and constitute an experience of community for those participants. Marginalized audience or real people, who are focused by Chautari Natak, rarely get opportunities to tell real stories in society. Storytelling in a public forum is a breakthrough in communication among participants, healing of the storyteller, and it can be a general issue for the transformation of the political and socio-cultural understanding. For the theoretical analysis, I employed Van Gennep's and Turner's concepts of liminality for the stage of storytelling and performance among the audience. The act of telling a personal story can be analyzed through the lens of Habermas' notion of communicative practice of everyday life.
\end{abstract}

Keywords: storytelling, Chautari Natak, harmony, liminality, dialogue

\section{Introduction}

Theatre Village, one of the theatre houses in Kathmandu, organized playback theatre $^{\dagger}$ for a month after April Earthquake in 2015. The primary purpose of the

*Dr. Giri has done PhD from Tribhuvan University and has been working as the Leturer in Anthropology at the Central Department of Anthropolgy, TU, Nepal.

'Playback Theatre (ChautariNatak in Nepali), is an interactive theatre form that is inspired by improvisational theatre, storytelling traditions, and psychodrama. It is based on the audience's personal 
playback theatre was listening (traumatic) stories of earthquake victims, making a community of people through participatory listening. Participatory engagement in the storytelling, listening, and enactment of the story (performance) promote 'collectivity' and 'we-feeling' among the participants. Jonathan Fox, the founder of playback theatre, has been visited Nepal several times to trained theatre artists about playback methodology, which has been used for the reconciliation of ex-combatant in the communities. Pro-public with technical support of CSSP-Berlin Centre for Integrative Mediation has been using the method to build reconciliation and social cohesion between ex-combatant and host communities and other cross-cultural conflicts in six districts of Nepal since 2015 (Pro-Public, 2017). Nepali theatre artists gave the Nepali name 'Chaurtari Natak' for playback theatre to give a traditional social and cultural flavor to Nepali communities.

Besides observing playback theatre in Theatre Village, series of discussion with theatre artists, and Jonathan Fox in Kathmandu, I have carried out fieldwork in the communities of six districts where Pro-public coordinated Chautari Nataks were performed on October 2015 and August 2016. I have observed Chatari Nataks at Binauna in Banke, Gulariya in Bardiya, Bijauri in Dang, Sainamaina in Rupandehi, Gaighat in Udayapur, and Bardibas in Mahottari performed by local artists. The basic logic of selection of these villages was that the Maoist army combatants called PLA (People Liberation Army) resettled and reintegrated in these communities after receiving the golden handshake from the government in 2012 (Pro-Public, 2017). In this context, the relations and social harmony between the ex-combatants and host community observed fragile because of political orientation. Pro-Public initiated social integration and harmony through Chautari Natak (Pro-Public, 2017). In Banke and Bardiya, local artists and dialogue facilitators organized and informed participants on scheduled time. The dialogue facilitators were selected from local communities including ex-combatants. One of the participants told his/her life story loudly in front of the artists and audience. Then, artists performed symbolically to disseminate meaning and feelings of the storyteller for the initiation of dialogue. The performance focused on social unity and harmony of people in the community irrespective of their caste, ethnicity, gender, political, and other socio-cultural status.

All of the selected communities were marginalized in terms of political economy, and mixed in terms of caste/ethnicity and regions. Tharu, Hill migrant Sukumbasi, excombatants, Dalits, and Brahmin-Chhetri were participants, and storytellers in the

stories, includes music, and improvised enactments and provides a vital source for individual emotional healing and the past's social processing. It was successfully organized at the community level in Nepal for the first time in 2015 through the zivik-funded project of CSSP and Pro Public, and continues for a month after earthquake 2015. 
community. When the participants heard one of the storytellers, many of them were interested to share their personal story in the forum. By sharing story, they started communication and dialogue with their social issues. In Kathmandu, Tamangs, disaster victims and stakeholders were selected because they participated on the performance of Chautari Nataks. The basic questions of the study are: What are the experiences of participants, and storyteller's aftermath of the earthquake disaster, insurgency, and caste ethnic conflict? Why did artists organize Chautari Natak in marginalized communities? How did storytelling promote social cohesion as claimed by theatre artists? What are the social and cultural assets of storytelling in the public sphere?

\section{Chautari Natak: Telling Private Story at the Public Sphere}

Chautari Natak was performed in different communities of six districts ${ }^{*}$ in 2015 and 2016. I observed Chautari Natak in Binauna-Banke and Gaighat-Udayapur. Artist/dialogue facilitators were selected among ex-combatants, host community, artist and social workers considering caste ethnic, gender, linguistic and regional inclusion by Pro-Public. Selected dialogue facilitator formed a management committee among the local people before performing the Nataks. With the coordination of the management committee, local artists called ordinary people to participate Chautari Natak. Local artists requested participant/spectator to tell their own story voluntarily on the stage about their own suffering, conflict, and any other experiences. All participants and artists listened to the story. When storyteller finished his/her story, artists performed the information without rehearsal and delay. After enactment, the storyteller was asked whether he/she was satisfied with the enactment of the story. Similarly, other 5/6 storyteller's stories were enacted in a session of Chautari Natak.

Chautari Natak can be observed and analyzed as a blending of traditional Nepali culture with the modern democratic practices. Storytelling is a widespread oral tradition of communication and dialogue in Nepal. The purpose of the storytelling is both entertainments as well as communication. When stories are enacted, they are supposed to joy, cultural morality, and social cohesion through dialogue between the characters. Abhi Subedi (2006) argued that street drama, poetry, theatrical performance, and cultural shows not only educate and change society but also promote social harmony and democratic culture in Nepal (Subedi, 2006). The term Chautari/Chautaro is a typical public sitting space where a formal and informal decisions, sharing, dialogue, and communication were made collectively. Its traditional connotation was sense of collectivity, a sense of justice, and model of communication in rural communities.

*Dang, Banke, Bardiya, Rupandehi, Mahottari, and Udayapur 
Usually, Chautari is constructed under Bar-Pipal* trees that are mythologically supposed to conjugating in-between. Such Chautari under Bar-Pipal is considered a place of security, psychological peace, a place of Yoga, meditation, and socio-cultural activities. The banner of the Chautari Natak has also painted the tree and the sitting places near a settlement. In another term, Chautari is a public space of laypeople, their space of sharing, social integration, and collective belongingness. The Chautari Natak symbolized both flavor of openness and space of marginalized people.

Similarly, women and marginalized people got the opportunity to share their stories in the public sphere. They hardly get a forum to share their suffering and experiences. One of the principal reasons for listening to the stories of women, as with Dalits, is that their lives are not generally accessible by other means, and their voices, and the underlying subversive messages they may contain, are too readily silenced in the more familiar, available and overtly self-important sources that serve the perspectives of the dominant group and gender. Sylvia Vatu (2004) notes that personal stories or life histories are a way of recovering the marginalized group's (women, Dalit, and ethnic) voice buried. For many marginalized groups, telling the lives of those who defied authority or exemplified a lost age of justice might serve as a 'weapon of the weak' (Scott, 1985). Performance artists were also laypeople who belonged to the same community. Chautari Natak is an opportunity of coming into the public sphere for women and marginalized people.

Krishna Khadka, a Chautari Natak artist from Mahottari District, said that people did not initially believe them (ordinary person) as an artist. He added that despite local artist and local story, people were interested in participating and listening stories of their own community members. At the end of the session at Mahottari, everybody asked, "When and where is the next show of Chautari Natak?" Krishna told me that wherever the Natak organized, lay-people participated in listening local stories. He said by giving logic of participation of women, and marginalized people, "stories are local and the artists are also local; therefore, participants find an organic flavor in the Chautari Natak performance."Soma Bahadur Barali, an older man from the Dalit community, shared his story on the stage of Chautari Natak at Patu-Bardibas in 2017. His story was about deprivation of equal share to his parental property because of his brother's affiliation with the insurgent group. He argued that this was his personal and family issue shared in the public sphere in the hope of social pressure for the integration of brothers. After performance of the Natak, some of participants expressed solidarity to initiate

*According to Hindu mythology Bar and Pipal are husband and wife. People believed that making decisions and sharing information by sitting under the trees have not only social but also cultural and religious values. People used to plant Bar-Pipal trees, organized marriage ceremonies of them and construct Chautari to earn merit as well as keep name memorable. 
communication with his brother. He lamented the loss of the traditional system of sharing happiness and pain. He added that Chautari Natak rolled reflection of Chautari justice and social space of sharing. Rama Rai, an ex-insurgent, told that her personal stories of war and suffering were told a public place to erase the negative attitude of communities toward her. After telling personal story on the Chautari, she was not only accepted but also appreciated by the participants. Similar opinions were shared by exinsurgent participants who were resettled at Rupandehi, Dang, Banke, and Bardiya districts. Other storytellers also said that they shared their personal stories at public gatherings because they rarely get the opportunity to share their experiences with many people. Especially women participants argued that they were overloaded by household chores, and Chautari Natak was the reason for their meeting, happiness, sharing, and understanding of marginalized people in the community. They demanded this program because it helped them to understand their fellow members better, build solidarity in case of suffering, and initiate communication for harmonious relations in the family and community.

In terms of communicative action, Chautari Natak resonated communicative lifeworld in which people reproduced their society through communication and dialogue. To emphasize an adequate framework Habermas (1984: xiv) notes to the communicative practice of everyday life, the medium of symbolic integration and reproduction:

In coming to an understanding with one another about the situation, participants in communication stand in a cultural tradition which they use and at the same time renew; in coordinating their actions via intersubjective recognition of criticizable validity claims, they rely on memberships in social groups and at the same time reinforce the integration of the latter; through participating in interaction with competent reference persons, growing children internalize the value orientations of their social groups and acquire generalized capabilities for action. . Under the functional aspect of reaching understanding communicative action serves the transmission and renewal of cultural knowledge; under the aspect of coordinating action, it serves social integration and the establishment of group solidarity; under the aspect of socialization, it serves the formation of personal identities.

Jurgen Habermas (1984) stressed the values of communicative action for the development of social harmony. When storytellers told their stories in front of familiar participants, they started a conversation with the public mass for personal issues. This public platform integrates people from different socio-political backgrounds. According to Suresh Baral, Chautari Natak revived communication and dialogue culture in the village. The Natak artists are dialogue facilitators who use the soft tools (art/ 
performance for discussion) to interact and integrate people. Communication is fundamental for an interactive society. The more people communicate, the more they understand each other. Similarly, Jonathan Fox* told me that storytelling was an elementary characteristic of humans. When people shared the same ontological level of human beings, they helped other humans for their satisfaction. Story and performative art have the power to serve people for life. In his book Acts of Service, he gives objectives of the playback with the following words: 'What is most important is to create a theatre that is neither sentimental nor demonic, hermetic not confrontational, but ultimately a theatre of love, happiness, and harmony' (Fox, 1994: 216). Chautari Natak followed his concept of happiness and social harmony by breaking the silence of marginalized people. The performance serves for the dialogue and integration that are fundamental prerequisites for a democratic society.

\section{Telling Lived Story}

In his novel Nausea, Jean-Paul Sartre writes that 'a man is always a teller of tales, he lives surrounded by his stories and the stories of others, he sees everything that happens to him through them, and tries to live his life as if he were recounting it' (Sartre, 2000:61). Playback theatre is organized around the stories of its participants; therefore, some consideration of the nature of narrative will be vital if we are to understand the peculiar performed stories told in playback. Similarly, W. Benjamin (1970) believed that oral storytelling was dying out because our sense of the 'epic side of truth, wisdom' (1970: 87) was lost, presumably through the reductionism of science and the privileging of 'information'. He says that the loss of this wisdom leads to a weakening of our idea of eternity and, by implication, death. The storyteller he writes: 'is the man (human) who could let the wick of his life be consumed completely by the gentle flame of his story' (Benjamin 1970:108). Similarly, since the 1920s, anthropologists have acknowledged life stories as powerful and riveting data for personalizing cultural, historical, and social forces (Narayan, 2004:227). By listening to life stories, politics, culture, and social processes could be analyzed.

In Chautari Natak, stories are simple but challenging to share. Every participant has a lived a story, but few interested participants told their own story. Local artists argued that most of the plots were about cross-cultural, cross-gender, political conflict, and economic hardship of marginalized communities. The core of the program is storytelling and participatory listening. Listening was participatory because all participants traveled together with the story's plot, and expressed sympathy, empathy,

${ }^{*}$ The founder of playback Theatre, Jonathan Fox, visited Nepal to train ChautariNatak (Nepali version of playback theatre) to national and local artists. Artists managed meeting with him at Kathmandu in 2016. 
and sociality. Chirimaya Tamang, one of the storytellers at Theatre Village aftermath of the earthquake, expressed that she became happy the first time after the earthquake by observing Playback Theatre. Her face was smiling. She added that many displaced women and elderly were interested in sharing their stories of loss and suffering, but there were not any contexts of sharing in the village. In Kathmandu, they were supported by different agencies and made coordinated for this storytelling and performance program. She admitted that she was not alone and the only sufferer of the earthquake disaster. She was trying to make connections with people both donor and affected. She thanked the organizer for giving her the opportunity of sharing her story. The overarching theme of the Chautari Natak is storytelling promotes social cohesion, and art can serve social harmony. Narendra Shrestha, one of the local artists of Chautari Natak from Bardiya, expressed his reflections:

Chautari Natak is more about the story rather than about performance. Simple performance skill is enough, but participatory listening is essential. Here, characters are not the focus of the participant; instead, storytellers are the main center of attraction. The tellers try to communicate lessons, education, or mere experience. Artists' message and creation are tough to understand among the participant in this site. Though I am a skilled artist for conventional performance, Chautari Natak is a new experience of performance. Many NGOs and government institutions contracted me to perform issues-based street drama in different parts of the district.

Shrestha believed that plot of the story and mood of the storyteller set the degree of seriousness of participants in Chautari Natak. The participant laughed when there was a comedy plot, and on the contrary, they cried when stories were pathetic and sentimental. Participants have no preoccupied mood. The dialogue facilitators argued that active listening of the story and participatory engagement are the necessary steps of a successful performance. Yubraj, a facilitator from Udayapur, reflects the program as:

It is different from conventional performances. Its focus is not performance. In the beginning, while I missed a portion of the story. At the time of performance, I lost myself. I realized that this was a totally unfair practice in Chautari Natak. Then, I corrected myself. I engaged in the story. I placed myself at the place of a storyteller; then, it was easy to embody the story. My performance depicted the themes of the storytellers.

Storytellers have a variety of responses to their experience of storytelling. Most of them said that they have hesitated initially, but when they started, they came up without fear and hesitation. Radha said that there was a dilemma in her mind whether to tell or not. When she heard a story from an earlier teller, she went on the stage to speak. She said her real-life story without hesitation. Storytelling participants were highly 
appreciated both by participants and local artists. One of the non-telling participants experienced a high degree of discomfort and uneasiness because she was also interested, but she controlled. She argued that she would have faced severe problems from her family members. In some contexts, the social and cultural protocols and values conflicted with the Chautari Natak's values. One of the artists at Mahottari said that women from sophisticated families could not share their personal stories in Chautari Natak because they did not think the forum was right place to tell and making personal public was loss of family status.

Anthropologists argued that storytelling were primordial practices of communication of knowledge of history, socialization of youngers, education, and social integrity from one generation to another. Jack Goody (2010) succinctly argued that oral story and the oral myth of the marginalized communities were distorted when they were mixed up with dominant cultural politics, religion and narratives. The dominant history, culture, and mythology influenced the making of characters and plots of the oral narratives. Therefore, the life of the oral history, mythology, and story was suppressed and infiltrated by politico economically dominant history and unequal relationships. Anthropologists have tended to view culture and ritual as performance (Turner, 1969, Douglas, 1966). Particular emphasis has been given to documenting the performative aspects of culture and society, e.g., initiations, tribal celebrations, seasonal festivals (Turner, 1974, 1986, Schechner, 1985, 1988). Sociologists claim that there is a theatre in everyday life (Read, 1993; Goffman, 1959). Goffman (1959) positions social behavior as performance, theorizing that we all perform as part of everyday life. He posits that performance refers to "all the activity of an individual which occurs during a period marked by his continuous presence before a set of observers and which has some influence on the observers (Goffman, 1959:22)." Victor Turner (1969) argued that stories were performed in a symbolic versions and gradually performative version of stories named rituals. Similarly, the playback theatre offers a contemporary ritual framework from within which individuals can engage with one another at the margins and pursue the magical interactions and rebirththat Berman (1990) claims as 'life-giving' like high castes' Bartabandha ritual gives cultural birth of the person. Jack Goody mentioned that a story-based performance form, playback theatre is derivative of the oral tradition (Goody, 2010), merging culturally relevant arts with sacred ritual, personal story, and community gatherings. He further notes that storytelling is a therapeutic method of healing and entertaining among the pre-literate community (Ibid). Narrative scholars argue that enabling such intimate interactions to occur in a public forum paves the way for societal and personal reform through stories. In terms of postquake trauma healing and social building, the process of playback theatre could be analyzed by Victor Turner's ritual theory of liminality. Van Gennep's three-phase 
schema, comprises a separation phase, a liminal (transition, threshold) phase, and a reentry phase (Turner 1969). The first phase is the pre-liminal phase is a painful, insecure feeling and quite a different world for the storyteller. The second stage that Turner and Gennep called liminal or the stage of ambiguity and confusion is quite similar to the stage of telling and performance. The images of oral narrative and participatory engagement are elementary forms of collective belonging among the participants. Turner (1982) claims that this liminal space invokes "anti-structure" and facilitates an experience of "communities", which Van Gennep (1960) called incorporation.

Literature from performance and ritual theory provide a framework for the inquiry of Chautari Natak. Theory about stories and storytelling offers a complementary lens that acknowledges the centrality of personal narrative on the public stage. Ethnographic observation of performances, informal interviews with artist and participants, and program reflexivity supported argument story telling is a method of transforming issues and agendas from private to public. Therefore, storytelling is a political dialogue and a form of a democratic way of communication. The case of postearthquake playback in Kathmandu, storyteller not only shared their experiences but also demanded socio-economic support from participants implicitly. The storytellers said that participatory engagement on story generated inter subjective feelings which were useful for trauma healing and collective belonging. The political-economic status and differences in physical dispositions are not obstacles to humanistic communication since they are positioned at the same level as the ontological scale (Viveiros de Castro, 2004). When participants, artist and storytellers shared same ontology, they understand each other and people in community better way. For this kind of personal storytelling to work in the modern context of the participant who begins the evening as strangersaccustomed to privacy and expecting to sit back and be entertained-it is essential to create an atmosphere of safety and respect. The actors, on stage throughout the performance, are receptive to the unknown roles they will be asked to play, and come back to their personalities between scenes. The story follows story as a collective drama is built, reflecting the lives of the people present.

\section{An Experience of Communitas*: Connection through Stories}

Chirimaya Tamang expressed her sense of collectivity among the storytellers and participants when she told the story of her loss and displacement by the earthquake. There were many displaced people in the hall. Participants were both publicly called

${ }^{*}$ Communitas is a Latin noun commonly referring either to an unstructured community in which people are equal, or to the very spirit of community. It also has special significance as a loanword in cultural anthropology and the social sciences. Communitas is an intense community spirit, the feeling of great social equality, solidarity, and togetherness. 
and requested some of the displaced people who were managed by the government at the open spaces of Kathmandu. Chirimaya shared with me that different people were interested in listening her story of the earthquake. She added that people who heard her story of disaster, tried to support both psychologically and materially. Some participants expressed sympathy, and empathy for her story. She said that more than material and food/shelter sense of social safety, hope and togetherness are energy for the forward life during an earthquake disaster. Her words indicated that experiences of communitas after living by and telling experiences among the participants in Kathmandu.

The concept of communitas is borrowed from Victor Turner's study of ritual stages: pre-liminal stage, liminal stage, and communitas stage (Turner, 1969). Local artists were from different cross-cultural groups. Participants of Chautari Natak shared that they reconsidered their previous roles and actions in the community. After participation, they were also interested in telling stories and experiences. They found that whatever they thought about the opponent was not right after listening to stories of fellow neighbors. One of the ex-PLA (people's liberation army) expressed his selfreflection of Chautari Natak was:

The beauty of Chautari Natak was that it focused on self-articulation, confession, and telling real life-story. People didn't understand the ex-PLA's feelings and experiences, because their experiences were so different from many local people's lived experiences. People remain detached and simply can't understand or see the relevance in terms of their own lives. After telling the life-experience of ex-PLA, the participants hugged and expressed sympathy upon me. They accepted me again as an ordinary people of the community. The great thing about Chautari Natak was that it focused on the emotion of the teller.

In 2006 a peace agreement was signed between the state and the Maoist People's Liberation Army (PLA), ending a decade-long armed conflict that killed over 13,000 people, displaced many more, and left wounds in the hearts of Nepalese citizens. The Maoist Army combatants were stationed in cantonments until the political agreement was found on the terms of their release. The United Nations Mission in Nepal verified about 19,602 of them as former combatants in 2007. In 2012, almost six years later, the cantonments were closed. Most ex-combatants $(18,250)$ set out for the villages after receiving a golden handshake from the government. In this sensitive context, the excombatants have been trying to settle and live as regular community members. There were problems of adjustment in the community because of their different behaviors. When ex-PLA participated and told their stories of insurgency, community people understood their compulsion and included in the community. The community's acceptance is analyzed with Turner's concept of communitas (being a mature member of the community after initiation ritual). 
Experiences of communitas occurred as participant members witnessed the telling and the dramatization of personal stories in Chautari Natak. It was during these times that participant members relaxed to watch and listen together. The heightened intra-personal activity generated by invitation to tell was (mostly) transformed when someone was selected to tell a story. At this time, the tension of participation abated, easing the expectation an individual may have placed on themselves to act. This shift resulted in a move away from heightened individualized engagement due to the possibilities of participation inherent in the form, to become other-focused. The participant shared the experience of listening and watching. It was a shift away from individual agency toward the formation of a collective watching participant. While there was no certainty that whole participants had an experience of communitas at every moment, the study found that many times during a performance some participant members shared a simultaneous experience of watching, listening, or reflecting. The sense of communitas was reinforced during the after-show period, which revealed that many participant members checked in with one another to ascertain how their experiences may have intersected. Communitas could be understood as a group experience of flow. Simultaneous experiences of flow among participant members equated to momentary experiences of communitas arising from a collective emotional response (e.g., laughter or tears) to a story or a spontaneously altered perspective and the simple sharing of applause. At the performances that feature in this study, several people in the participant were found to simultaneously identify with the teller or other characters presented in a story. There were also participant members who had little collective engagement with a story. Often this was transformed when the story was dramatized. Mostly, the teller's performance was a unique and compelling collective experience. Some participant members experienced communitas through a shared aversion to listening to a particular teller.

\section{Chautari Natak: A Metaphor for Community}

The term 'Chautari' connotes the revitalization of communal life in Nepali culture. Traditionally, farmers, porter, visitor, and community people not only get rest under poplar trees but also make gossip, meeting, and decision on Chautari. It is a social place as well as a cultural space where poplar trees not only provide oxygen but also a sense of protection, justice, and belongingness. Jurisdiction under poplar trees is considered as a witness of God (poplar tree is an incarnation of God among Hindu people). Socially, it is an open place where anybody can come and participate. Politically, Chautari is a democratic space. In this way, the storytelling and performance activities captured the traditional concept of the community. I discuss the notion that the Chautari Natak is a metaphor for society. Conceived as a public event, 
the community-based Natak performance places emphasis on local stories as a means of connection and building community. The immediacy of the storytelling performances and the dramatic transformations of them on stage provide multiple metaphors for a community experience. It challenged mainstream theatrical performance, the sophisticated plot of theatre, and the dominant social protocols in the community context. Sunita Rai, one of the storytellers on Chautari Natak, said, "Stories are local and the artists are also local; therefore, participants find organic flavor on the Chautari Natak performance."Participants respond by either accepting or rejecting the challenge, and thus entering or resisting the liminal experience. The call to risk is reacted by participant participation and is reliant on individual agency.

Chautari Natak summons participants active listening. Unlike the individual agency underpinning the necessary culture of risk-taking the call to listen engenders collective action. The performance is a counter-cultural social environment where people are encouraged to share stories. This requires all participants (without hierarchy), listening for what's being said, what's being shown, and missing. In terms of the development of human agency (capacity to act despite constraints) among marginalized groups, the Natak could be further studied in this perspective. In some stories, issues were trivial, but they were necessary for marginalized people. The Natak provides space for trivial matters of laypeople that demands further analysis in terms of 'small is beautiful,' and lay life matter.

\section{Conclusion}

Chautari Natak is an interactive form of theatre based on the personal stories of local participants. In the Natak (a performance), a series of stories are spontaneously told by volunteer tellers. Each tale is then paired with a discrete dramatic enactment inspired by the particular plot, mood, and images inherent in the 'just-told' narrative. A story-based performance form, Chautari Natak is derivative of the oral tradition merging culturally relevant arts with sacred ritual, personal story, and community gatherings. The Natak combines cultural ingredients of oral narratives and ritual performance by its names and content. Stories and performances are straightforward, accessible to marginalized community members, and anti-structural in terms of the social hierarchy of communication. In general contexts, elites did not share, listen, and communicate trivial issues with laypeople. Participants not only sit together but also interact, listen, and they communicate with other participants, which leads towards harmonious social relations or communitas.

In this way, the Chautari Natak method enables everyone to take responsibility for the telling spaces shared. This generates a spirit of inquiry and curiosity about the other. The Natak opens a space where people can meet in their sameness and difference 
and potentially rise above estrangement and judgment. As an ephemeral community experience, the Natak offers a chance for participant members to see others in a different light and perhaps overcome estrangement by knowing and understanding more about them. The mutuality implicit in the form means that this may create reciprocal opportunities for seeing and coming to know more of the Other. These public reflexive Nataks promote insight, with participants members thinking about what they think and feel or, perhaps more significantly, discussing what they think and believe. Experiences that foster the erosion of social distance due to reflection, or as a result of discussion between individuals because of perceived difference, no matter how small or intangible, represent an opportunity for a community. At many of the study performances, several people referred to the importance of hearing the stories of the others, from bureaucrats hearing the stories of people with mental illness to older women hearing the stories of younger women. This hearing practice might be termed 'a community narrative' (Rapapport, 2000) that embodies the shared experience of the performance and the stories told within the performance. Like an oral history that evokes the tradition and lore of the gathered participant, Chautari Natak elucidates multiple truths and celebrates the courage and social coherence of the participant/community. Future researchers could analyze the Chautari Natak through the lens of human agency development, trivial issue matter, the resistance of marginalized groups, and subaltern studies.

\section{Acknowledgments}

This article has been completed with the support of numerous people and institutions in many places. My most profound debt is to officer of Pro-Public, who gave me the opportunity to evaluate Chautari Natak in 2015 and 2016. I am thankful to Prof. Binod Pokharel for his cooperation and inspiration to write academic articles. I am grateful to Jonathan Fox, the founder of playback theatre, Jeebesh Rayamajhi, the founder of Theatre Village. I am grateful to artists and informants who provided the critical data in different districts.

\section{References}

Benjamin, W. (1970). The storyteller: Reflections on the works of Nikolai Leskov. In W. Benjamin (ed.). Illuminations. London: Collins/Fontana.

Berman, M. (1990). Coming to our senses: Body and spirit in the hidden history of the west. NY: Bantam Books.

Douglas, M. (1966). Purity and danger. London: Routledge and Kegan Paul.

Fox, J. (1994). Acts of service: Spontaneity, commitment, tradition in the nonscripted theatre. New Paltz: Tusitala Publishing. 
Fox, J. and Dauber, H. (eds) (1999). Gathering voices: Essays in playback theatre. New Paltz, New York: Tusitala Publishing.

Goffman, E. (1959). The presentation of self in everyday life. NY: Doubleday.

Goody, J. (2010). Myth, ritual and the oral. Cambridge: Cambridge University Press.

Habermas, J. (1984). The theory of communicative action: Reason and the rationalization of society. Boston: Beacon Press.

Nayaran, K. (2004). Honor is honor, after all: Silence and speech in the life stories of women in Kangra, North-West India. In D. Arnold and S. Blackburn, (eds.), Telling lives in India: Biography, autobiography and life history, (Pp. 227-251). Bloomington: Indiana University Press.

Pro-Public. (2017). Enacting Dialogue - Community Level Reconciliation through Theatre-Facilitated Dialogue. External Evaluation Report, Pro-Public.

Rappaport, J. (2000). Community narrative: Tales of terror and joy. American Journal of Community Psychology 28(1), 1-24.

Read, A. (1993). Theatre and everyday Life: an ethics of performance. London, NY: Routledge.

Sartre, J. P. (2000). Nausea. London: Penguin.

Schechner, R. (1985). Between theatre and Anthropology. Philadelphia: University of Pennsylvania Press.

Schechner, R. (1988). Performance theory. NY: Routledge.

Scott, J. C. (1985). Weapons of the weak: Everyday forms of peasant resistance.

London: Yale University Press.

Subedi, A. (2006). Nepali theatre as I see. Kathmandu: Gurukul.

Turner, V. (1969). The ritual process. London: Routledge and Kegan Paul.

Turner, V. (1974). Dramas, fields and metaphors. NY: Cornell University Press.

Turner, V. (1982). From ritual to theatre: the human seriousness of play. NY: PAJ Publications.

Turner, V. (1986). The anthropology of performance. PAJ Publications, NY.

Van Gennep, A. (1960). The rites of passage. M. B. Vizedom and G. L. Caffee (Trans. \& eds.). London: Routledge and Kegan Paul.

Vatuk, S. (2004). HamaraDaur-i Hayat: An Indian Muslim woman writes her life. In D. Arnold and S. Blackburn, (eds.), Telling lives in India: Biography, autobiography and life history, (Pp. 144-174). Bloomington: Indiana University Press.

Viveiros de Castro, E. (2004). Exchanging perspectives: The transformation of objects into subjects in Amerindian ontologies. Common Knowledge, vol. 1 0/3: 463-84. 